\title{
LISTADO DE EVALUADORES
}

Los estudios y artículos recibidos en CLARIDADES. REVISTA DE FILOSOFÍA son sometidos a un proceso de arbitraje ciego por dos informantes externos, los cuales se ocupan de evaluar el contenido y la metodología de los artículos. Todos los artículos tienen una revisión previa por parte del equipo directivo de la revista, para comprobar que los artículos cumplen los requisitos mínimos. Los autores reciben un resumen de los informes redactados por los revisores, indicándoles -si así es el caso- la manera de subsanar deficiencias o realizar los cambios que se solicitan. Los informantes son seleccionados de acuerdo a un criterio de excelencia académica e investigadora, y tomando en consideración que su ámbito de especialización se corresponda con las temáticas abordadas en cada uno de los artículos. En este número de la revista han colaborado como informantes las siguientes personas:

Diego Ramírez Fernánndez (Universidad de Málaga, España)

Francisco Alcalá Rodríguez (Universidad de Granada, España)

José Antonio Espinosa Garzón (Universidad de Málaga, España)

Juan A. García González (Universidad de Málaga-FICUM, España)

Lucas Risoto de Mesa (Universidad de Málaga, España)

Oscar Cubo Ugarte (FernUniversität Hagen, Alemania)

Paloma García Briones (Colegio San José Estepona, España) 